\title{
Seminal Levels of Immunoglobulins and Complements and Their Relationship with Seminal Parameters in Chronic Hemodialytic Patients
}

\author{
Gilmar P Silva ${ }^{1}$, Vítor PX Grangeiro ${ }^{2}$, Carmelita FD Oliveira ${ }^{3}$
}

\begin{abstract}
Aim and objective: To investigate the potential relationship between seminal complements (C3 and C4) and immunoglobulin (IgA and IgG) levels and seminal parameters (SPs) in chronic hemodialysis patients.

Materials and methods: A cross-sectional study was conducted among patients aged between 18 years and 60 years. The sample comprises 60 males undergoing hemodialysis for $>6$ months, and 15 healthy males without clinical or laboratory signs of genitourinary and eugonadic tract infections. Spermograms and leukocytopermia, serum hormonal profiles, and seminal measurements of complement fractions (C3, C4) and immunoglobulins (IgA, IgG) were performed.

Results: The hemodialysis and healthy groups were similar in age $(49.47 \pm 05.55$ and $50.53 \pm 04.24$ years, $p=0.06)$. Average levels of seminal $C$ fractions $(\mathrm{C} 3, \mathrm{C} 4)$ were similar between the hemodialysis and healthy groups, between normozoospermia and oligozoospermia hemodialysis subgroups, and in the oligozoospermia hemodialysis subgroup. Average seminal levels of Igs (A and $G$ ) differed significantly between the hemodialysis and healthy groups (351.60 $\pm 035.80 \mathrm{vs} 247.40 \pm 39.00 \mathrm{mg} / \mathrm{L})$, and in normozoospermia and oligozoospermia hemodialysis subgroups ( $361.20 \pm 36.30$ vs $340.60 \pm 32.50 \mathrm{mg} / \mathrm{L})$. However, they were similar $(p>0.05)$ between subgroups of oligozoospermia. The seminal fractions of complete (C3 and $C 4)$ and lg (A and $\mathrm{G})$ did not correlate $(p>0.05)$ with SPs. All participants had hormonal profiles within the normal range.

Conclusion: The complement fractions (C3 and C4) and immunoglobulins (IgA and $\lg G$ ) showed no relationship with SPs in chronic hemodialysis patients.

Keywords: Chronic kidney disease, Complement, Immunity, Immunoglobulins, Male infertility.

International Journal of Infertility and Fetal Medicine (2021): 10.5005/jp-journals-10016-1214
\end{abstract}

\section{INTRODUCTION}

Seminal plasma has long been studied in search of proteins that may be related to the changes identified in the seminal parameter (SP). These may be used in clinical practice to explain the different clinical presentations of subfertility. ${ }^{1}$ Infertility affects approximately $10 \%$ of couples worldwide, with male factor participation in $25 \%$ of cases. $^{2}$ Changes in SP on the sperm test (concentration, motility, vitality, and morphology) are identified in approximately $50 \%$ of men with altered fertility. ${ }^{3}$

Chronic kidney disease, especially chronic hemodialysis, is accompanied by complaints of subfertility or infertility. This is due to several factors that directly or indirectly compromise spermatogenesis, and consequently, the seminal quality. These factors include hypogonadism, ${ }^{4}$ uremia, ${ }^{5}$ infection and inflammation, ${ }^{6}$ reactive oxygen species, ${ }^{7}$ and immunological alterations. ${ }^{8}$ The significance of changes in fertility in these patients is neglected due to the visible complications resulting from complete renal failure and the dependence on hemodialysis. Thus, few studies have investigated the pathophysiology of infertility in these patients. Prem et al. ${ }^{9}$ found over $40 \%$ of chronic uremic patients with oligozoospermia or azoospermia.

However, regarding the serum compartment, the negative systemic effects of end-stage renal disease and hemodialysis are widely implicated in promoting vital immune reactions with repercussions for all body systems. These include low-grade systemic inflammation, ${ }^{10}$ oxidative stress, ${ }^{7}$ consumption of serum
${ }^{1}$ Department of Physician, Medicine, University of Brasilia, Brasília, Brazil

${ }^{2,3}$ Medicine Department, School of Medical Sciences of João Pessoa, João Pessoa, Paraíba, Brazil

Corresponding Author: Gilmar P Silva, Department of Physician, Medicine, University of Brasilia, Brasília, Brazil, Phone: +5561981225458, e-mail: gilpsilva2006@gmail.com

How to cite this article: Silva GP, Grangeiro VPX, Oliveira CFD. Seminal Levels of Immunoglobulins and Complements and Their Relationship with Seminal Parameters in Chronic Hemodialytic Patients. Int J Infertil Fetal Med 2021;12(1):13-16.

Source of support: University of Brasília

Conflict of interest: None

complement (C) fractions, ${ }^{8}$ and dysregulation of the innate/ adaptive immune system. ${ }^{11}$

Significant immunological changes in the systemic compartment affect patients with end-stage renal disease, such as consumption of $C$ fractions and immunoglobulins (Igs). ${ }^{8,11}$ Few studies have evaluated the repercussions in the testicular compartment of systemic changes in $\mathrm{C}$ and Igs fractions and their potential contributions to the pathophysiology of fertility changes among these patients.

Given the high seminal concentration of $C$ and Igs fractions and the current research gap on the immunoregulatory activities

(c) Jaypee Brothers Medical Publishers. 2021 Open Access This article is distributed under the terms of the Creative Commons Attribution 4.0 International License (https://creativecommons.org/licenses/by-nc/4.0/), which permits unrestricted use, distribution, and non-commercial reproduction in any medium, provided you give appropriate credit to the original author(s) and the source, provide a link to the Creative Commons license, and indicate if changes were made. The Creative Commons Public Domain Dedication waiver (http://creativecommons.org/publicdomain/zero/1.0/) applies to the data made available in this article, unless otherwise stated. 
of these molecules in seminal plasma, we aimed to evaluate the relationship between seminal $C$ fractions ( $C 3$ and $C 4$ ), Igs ( $A$ and $\mathrm{G})$, and SP in chronic hemodialysis patients.

\section{Materials and Methods}

A cross-sectional study was conducted in the hemodialysis department of the University Hospital of the University of Brasília, from July 2016 to December 2016. Patients were aged 18-60 years and had no diagnosis of hypogonadism and hyperprolactinemia. This study was approved by the Research Ethics Committee of the Faculty of Health Sciences of the University of Brasília (approval number 53172316.9.0000.0030).

Patients with a recent history of genitourinary tract infection, prostatitis, criptoquidia, and varicocele were excluded from the study.

The sample comprises 60 males undergoing hemodialysis for over 6 months, and 15 healthy males from the same hospital without changes in SPs.

The group of males undergoing hemodialysis with oligozoospermia were divided into three subgroups based on seminal sperm concentration: severe oligozoospermia $(n=5$; sperm concentration $<5 \times 10^{6} / \mathrm{mL}$ ), moderate oligozoospermia ( $n$ $=9 ; 5 \times 10^{6} / \mathrm{mL} \leq$ sperm concentration $<10 \times 10^{6} / \mathrm{mL}$ ), and mild oligozoospermia $\left(n=14 ; 10 \times 10^{6} / \mathrm{mL} \leq\right.$ sperm concentration $<15$ $\times 10^{6} / \mathrm{mL}$ ).

Leukocytospermia was defined as the presence of more than one million leukocytes $/ 1 \mathrm{~mL}$ of semen. ${ }^{12}$

The hemodialysis and healthy groups contributed biological materials (blood and semen) on the same day, between 08:00 and 10:00 a.m. in the clinical analysis laboratory at the same hospital. Blood samples were collected to measure the serum hormonal profile (follicle-stimulating hormone, luteinizing hormone, prolactin, and total testosterone). Semen samples were obtained by voluntary masturbation in an appropriate environment at $37^{\circ} \mathrm{C}$ for conducting manual spermograms. This was done according to the processing guidelines of human semen from the World Health Organization (WHO) 5 th edition. ${ }^{12}$ The semen was centrifuged at $3500 \times g$ for 20 minutes after 30 minutes of liquefaction. The supernatant was collected and stored at $20^{\circ} \mathrm{C}$ for later measurement of $C(C 3, C 4)$ and Igs $(A, G)$ levels by immunoassay using a BNII immunonephelometer (Dade Behring), with specific kits recommended by the manufacturer.

Normality tests were applied to the quantitative variables. The most appropriate statistical test was applied to verify the differences or correlations between the study variables. The statistical significance was set at $p<0.05$. Analyses were conducted using IBM SPSS ${ }^{\circledast}$ for Windows, version 20.0.

\section{Results}

The hemodialysis and healthy groups were similar in age (49.47 \pm 05.55 and $50.53 \pm 04.24$ years, respectively; $p=0.06$ ). Average levels of seminal $C$ fractions $(C 3, C 4)$ were similar between the hemodialysis and healthy groups, in normozoospermia and oligozoospermia subgroups, and in the subgroups of oligozoospermia (Table 1). Average seminal levels of Igs ( $A$ and $G$ ) differed significantly between the hemodialysis and healthy groups ( $351.60 \pm 035.80$ vs $247.40 \pm 39.00 \mathrm{mg} / \mathrm{L}$ ), and in normozoospermia and oligozoospermia hemodialysis subgroups (361.20 \pm 36.30 vs $340.60 \pm 32.50 \mathrm{mg} / \mathrm{L})$. However, they were similar $(p>0.05)$ between the subgroups of oligozoospermia (Table 1). The seminal fractions

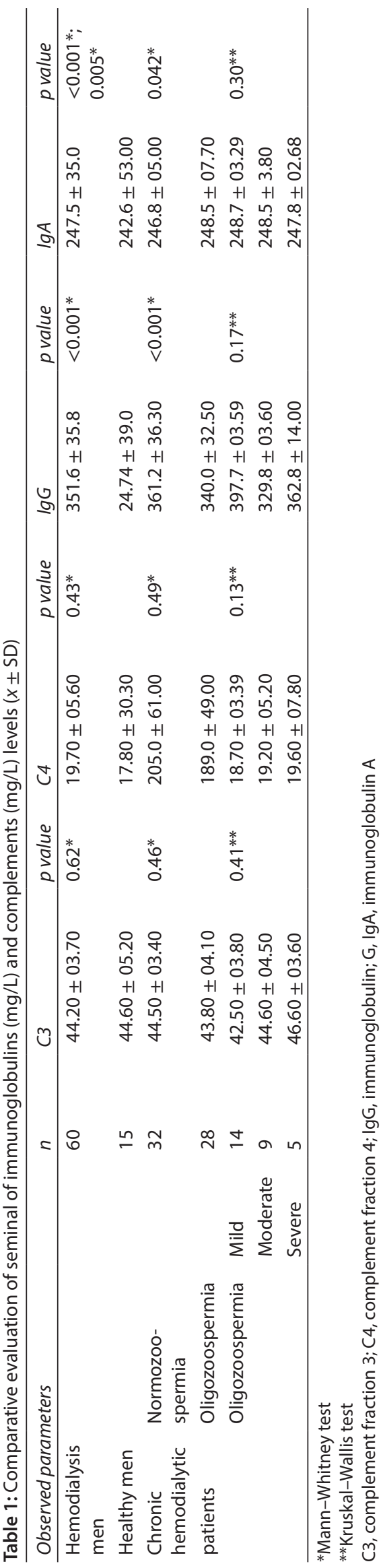


of complete (C3 and C4) and Ig (A and G) did not correlate ( $p>0.05$ ) with SP (Table 2). All participants had hormonal profiles within the normal range.

\section{Discussion}

The relationship between immunological factors and seminal quality is well established in the literature but remains controversial. Previous studies have demonstrated and recognized the contribution of anti-sperm antibodies in the pathophysiology of male infertility. ${ }^{13}$ Furthermore, other molecules have been studied regarding the complement system $(\mathrm{SC})^{14}$ and Igs. ${ }^{15}$ The SC comprises proteins produced in the liver or expressed on the cell membrane surface, operating in plasma, tissues, or inside cells. ${ }^{14}$ It is accepted that SC activation triggers proteolysis, which generates enzyme complexes with important proteolytic activity in the innate immune response, host homeostasis, inflammation, and defense against pathogens. $^{14,16}$

The C3 fraction is the main component of SC. It is responsible for cellular proteolytic activity and plays a crucial role in adaptive immunity by inducing the production of antibodies by $B$ cells responsible for the production of immunoglobulins. ${ }^{15}$ Cellular mucus membranes produce $70 \%$ of circulating immunoglobulins, and the remainder is produced by lymphoid organs such as the bone marrow, spleen, and lymph nodes. ${ }^{17}$

Seminal lgs originate from prostate secretion and less systemic immune compartment due to blood transudation into the seminal plasma. ${ }^{18}$ The similar ages of the healthy and hemodialysis groups gave greater credibility and reduced the bias in the interpretation and analysis of this variable.

Our results suggest that seminal levels of complement fractions $(\mathrm{C} 3, \mathrm{C} 4)$ are indifferent to changes in SP and the lgs (A and $\mathrm{G})$. This is despite the significant differences between the hemodialysis and healthy groups, and in the subgroups of oligozoospermia. Furthermore, the hemodialysis group indicated no correlation with changes in SP. These results are partially corroborated by previous research. For example, Limam et al. ${ }^{15}$ studied 17 patients with altered fertility using an immunonephelometer. They found average levels of $\mathrm{IgG}(83.3 \mathrm{mg} / \mathrm{L})$ and $\mathrm{lgA}(33.6 \mathrm{mg} / \mathrm{L})$ which were significantly different in healthy males and were associated with SPs. Toama et al. ${ }^{19}$ analyzed a sample of 34 males with idiopathic infertility disorders. They found higher levels of seminal $\lg A$ and IgG in azoospermia and normozoospermic males compared with healthy fertile males, but within the normal range. In the same study, mean levels of seminal complement fractions $(C 3, C 4)$ in males with teratospermia and asthenospermia were lower than those of healthy males. Rahimi et al. ${ }^{20}$ studied the contribution of anti-sperm antibodies in the physiopathology of men with altered fertility. They verified the correlation between complement fractions C3 and SP, regardless of the positivity for the studied antibodies, anti-sperm antibodies $+(r=0.522, p<0.001)$, and anti-sperm antibodies $(r=$ $0.451, p<0.001)$.

The conflicting results in the literature can be partially explained by the non-evaluation of leukocytospermia, and varying methods used in the measurement of Igs and $C$ in the seminal samples of previous research. The determination of leukocytospermia in the present study may have eliminated the bias of the inflammatory factor of the genital tract and its influence on the seminal levels of the $C$ and lgs fractions. ${ }^{21,22}$

The mechanism by which complement fractions (C3, C4) and Igs $(A, G)$ are related to $S P$ is unknown. However, it is considered to be an ingenious and orchestrated mechanism of these proteins ( $C$ and $\mathrm{Ig}$ ) in innate and adaptive immune responses. ${ }^{23}$ These responses include the opsonization of pathogens, control of sperm apoptosis, regulation of seminal pro and anti-inflammatory cytokines, and the production of local immunoglobulins. ${ }^{24}$

The altered serum levels of $C$, Igs, and other systemic factors implicated in the pathophysiology of infertility by direct or indirect action can alter the testicular immune-privileged ${ }^{25}$ condition. This promotes an increase in the permeability of the hematotesticular barrier to these substances, interfering with the complex mechanism of spermatogenesis. ${ }^{26}$ This results in changes

Table 2: Correlational evaluation Spearmen's between seminal immunoglobulins and complements and seminal parameters

\begin{tabular}{|c|c|c|c|c|c|}
\hline & & \multicolumn{2}{|c|}{ Case $(n=60)$} & \multicolumn{2}{|c|}{ Control $(n=15)$} \\
\hline \multicolumn{2}{|c|}{ Observed parameters } & $r$ & $p$ & $r$ & $p$ \\
\hline \multirow[t]{4}{*}{$\mathrm{C} 3$} & Sperm density & 0.058 & $>0.05$ & -0.456 & $>0.05$ \\
\hline & Sperm motility & 0.168 & $>0.05$ & -0.420 & $>0.05$ \\
\hline & Sperm viability & 0.017 & $>0.05$ & -0.184 & $>0.05$ \\
\hline & Sperm morphology & 0.096 & $>0.05$ & -0.595 & $>0.05$ \\
\hline \multirow[t]{4}{*}{ C4 } & Sperm density & 0.230 & $>0.05$ & 0.206 & $>0.05$ \\
\hline & Sperm motility & 0.099 & $>0.05$ & 0.257 & $>0.05$ \\
\hline & Sperm viability & -0.019 & $>0.05$ & -0.486 & $>0.05$ \\
\hline & Sperm morphology & 0.101 & $>0.05$ & 0.239 & $>0.05$ \\
\hline \multirow[t]{4}{*}{$\lg G$} & Sperm density & 0.247 & $>0.05$ & -0582 & $>0.05$ \\
\hline & Sperm motility & 0.216 & $>0.05$ & -0.598 & $>0.05$ \\
\hline & Sperm viability & 0.066 & $>0.05$ & -0.051 & $>0.05$ \\
\hline & Sperm morphology & 0.151 & $>0.05$ & -0.384 & $>0.05$ \\
\hline \multirow[t]{4}{*}{$\lg A$} & Sperm density & -0.177 & $>0.05$ & 0.203 & $>0.05$ \\
\hline & Sperm motility & -0.156 & $>0.05$ & 0.158 & $>0.05$ \\
\hline & Sperm viability & -0.233 & $>0.05$ & 0.206 & $>0.05$ \\
\hline & Sperm morphology & -0.173 & $>0.05$ & -0.209 & $>0.05$ \\
\hline
\end{tabular}

C3, complement fraction 3; C4, complement fraction 4; lgG, immunoglobulin G; lgA, immunoglobulin A 
in seminal quality, presenting as male subfertility or infertility. The limitations of this study included the absence of anti-sperm antibodies, complement regulator seminal measurement, and reduced sample size.

\section{CONCLUSION}

The complement fractions (C3 and $\mathrm{C} 4$ ) and immunoglobulins (IgA and IgG) showed no relationship with SPs among chronic hemodialysis patients.

\section{Informed Consent}

Informed consent was obtained from all individual participants included in the study.

\section{References}

1. Sergeant N, Mitchell V, Jumeau F, et al. Methods for determining human sperm quality. Google Patents 2017.

2. Gupta R, Kaur S, Bhagat B, et al. Epidemiology of infertility patients with abnormal semen parameters. Indian J Appl Res 2019;9(7):e5122.

3. Hamilton JAM, Cissen M, Brandes M, et al. Total motile sperm count: a better indicator for the severity of male factor infertility than the WHO sperm classification system. Hum Reprod 2015;30(5):1110-1121. DOI: 10.1093/humrep/dev058.

4. Neuzillet $Y$, Thuret R, Kleinclauss $F$, et al. Andrologic consequences of chronic renal failure: state of the art for the yearly scientific report of the French National Association of Urology. Prog Urol 2016;26(15):1088-1093. DOI: 10.1016/j.purol.2016.08.013.

5. Dumanski SM, Ahmed SB. Fertility and reproductive care in chronic kidney disease. J Nephrol 2019;32(1):39-50. DOI: 10.1007/s40620-01800569-9.

6. Raj DS, Pecoits-Filho R, Kimmel PL. Inflammation in chronic kidney disease. Chronic Renal Disease. Elsevier; 2020. pp. 355-373.

7. Russa DL, Pellegrino D, Montesanto A, et al. Oxidative balance and inflammation in hemodialysis patients: biomarkers of cardiovascular risk? Oxidat Med Cellu longev 2019;2019:8567275. DOI: 10.1155/2019/8567275.

8. Poppelaars F, Faria B, Gaya da Costa M, et al. The complement system in dialysis: a forgotten story? Front Immunol 2018;9:71. DOI: 10.3389/ fimmu.2018.00071.

9. Prem AR, Punekar SV, Kalpana M, et al. Male reproductive function in uraemia: efficacy of haemodialysis and renal transplantation. $\mathrm{Br} J$ Urol 1996;78(4):635-638. DOI: 10.1046/j.1464-410X.1996.14624.x.
10. Yilmaz MI, Carrero JJ, Axelsson J, et al. Low-grade inflammation in chronic kidney disease patients before the start of renal replacement therapy: sources and consequences. Clin Nephrol 2007;68(1):1-9. DOI: 10.5414/CNP68001.

11. Brazdova A, Senechal H, Peltre $G$, et al. Immune aspects of female infertility. Int J Fertil Steril 2016;10(1):1.

12. Organization $\mathrm{WH}, \mathrm{WHO}$ laboratory manual for the examination and processing of human semen. 2010.

13. Said TM, Agarwal A. Tests for sperm antibodies. Immune Infertility. Springer; 2017. pp. 197-207.

14. Delanghe JR, Speeckaert R, Speeckaert MM. Complement C3 and its polymorphism: biological and clinical consequences. Pathology 2014;46(1):1-10. DOI: 10.1097/PAT.0000000000000042.

15. Limam $M$, Zorgati $M$, Zarrouk $A$, et al. Ig G and lgA levels determination in semen liquid: interest for the biological investigation of infertility. Ann Biol Clin (Paris)+A4255 2009;67(6):613-617.

16. Merle NS, Noe R, Halbwachs-Mecarelli L, et al. Complement system part II: role in immunity. Front Immunol 2015;6:257. DOI: 10.3389/ fimmu.2015.00257.

17. Sun $Y$, Huang $T$, Hammarstrom $L$, et al. The immunoglobulins: new insights, implications, and applications. Annu Rev Anim Biosci 2020;8(1):145-169. DOI: 10.1146/annurev-animal-021419-083720.

18. Silva JAF, Biancardi MF, Stach-Machado DR, et al. The origin of prostate gland-secreted IgA and IgG. Sci Rep 2017;7(1):16488. DOI: 10.1038/ s41598-017-16717-3.

19. Toama R, Al-Salman AR, AI-Barrak AAY. Study of the immunological state of patients with idiopathic male infertility. Med J Baby 2006;3(34):246-254.

20. Rahimi A, Sepehri H, Pakravesh J, et al. Quantification of C3 and C4 in infertile men with antisperm antibody in their seminal plasma. Am J Reprod Immunol 1999;41(5):330-336. DOI: 10.1111/j.1600-0897.1999. tb00446.x.

21. Ghebrehiwet $\mathrm{B}$. The complement system: an evolution in progress. F1000 Res 2016;5:2840. DOI: 10.12688/f1000research.10065.1.

22. Azenabor A, Ekun AO, Akinloye O. Impact of inflammation on male reproductive tract. J Reproduct Infertil 2015;16(3):123-129.

23. Qu N, Ogawa $Y$, Kuramasu $M$, et al. Immunological microenvironment in the testis. Reproduct Med Biol 2020;19(1):24-31. DOI: 10.1002/ rmb2.12293.

24. Archana SS, Selvaraju S, Binsila BK, et al. Immune regulatory molecules as modifiers of semen and fertility: a review. Molecul Reproduct Develop 2019(11). DOI: 10.1002/mrd.23263.

25. Fijak M, Bhushan S, Meinhardt A. The immune privilege of the testis. Immune Infertil. Springer; 2017. pp. 97-107.

26. Chen $Q$, Deng T, Han D. Testicular immunoregulation and spermatogenesis. Semin Cell Dev Biol 2016;59:157-165. DOI: 10.1016/ j.semcdb.2016.01.019. 